\title{
A violência contra as mulheres idosas: tipicidade, características e significados
}

\section{Violence against elderly women: typicality, characteristics and meanings}

DOI: $10.46919 / \operatorname{archv} 1 \mathrm{n} 5-008$

Recebimento dos originais: 10/07/2020

Aceitação para publicação: 30/08/2020

\author{
Aline Oliveira Silva \\ Doutora em Economia Doméstica, pela Universidade Federal de Viçosa (UFV), Minas Gerais, Brasil. \\ Instituição: Universidade Federal de Viçosa (UFV), Minas Gerais, Brasil \\ Campus Universitário, Viçosa, Minas Gerais \\ CEP: 36576-000 \\ E-mail: aline.o.silva@ufv.br \\ Maria das Dores Saraiva de Loreto \\ Pós-Doutora em Família e Meio Ambiente pela University of Guelph, Guelph, Canada \\ Instituição: Universidade Federal de Viçosa (UFV), Minas Gerais, Brasil \\ Campus Universitário, Viçosa, Minas Gerais \\ CEP: 36576-000 \\ E-mail: mdora@ufv.br

\section{Rita de Cássia Bhering Ramos} \\ Mestre em Economia Doméstica pela Universidade Federal de Viçosa (UFV), Minas Gerais, Brasil. \\ Instituição: Universidade Federal de Viçosa (UFV), Minas Gerais, Brasil \\ Campus Universitário, Viçosa, Minas Gerais \\ CEP: 36576-000 \\ E-mail: rcbramos@bol.com.br
}

\section{RESUMO}

O crescimento acelerado da população idosa e o aumento da violência intrafamiliar contra esse grupo vulnerável, conjugado ao fato de que muitas mulheres desconhecem as leis e órgãos de proteção, sendo agredidas em silêncio, incentivou a realização desse trabalho, que objetivou analisar a tipicidade, características e significados da violência contra a mulher idosa. A pesquisa, de natureza quantiqualitativa foi realizada na cidade de Viçosa/MG, tendo como público alvo mulheres vítimas de violência, sendo utilizadas as seguintes técnicas: pesquisa documental, entrevista semiestruturada e o TALP. As informações foram coletadas junto a Policia Civil, onde se constatou 17 ocorrências de violência doméstica contra mulheres idosas. Além disso, foram analisados 80 processos instaurados de mulheres, que recorreram às medidas protetivas de combate à violência, sendo quatro processos de mulheres idosas. Os resultados evidenciaram que a violência doméstica contra a mulher tende a ocorrer no ambiente familiar, demonstrando suas relações assimétricas e conflitivas. Quanto à tipicidade, constatou-se predominantemente a violência psicológica, seguida da violência física. Assim pode-se concluir que a violência contra a mulher idosa é um fenômeno complexo, multifacetado, dinâmico e de difícil controle, que ocorre principalmente no espaço intrafamiliar, causando dor, tristeza, raiva e humilhação.

Palavras-Chave: Violência, Mulher idosa, Tipicidade, Características, Significados. 


\begin{abstract}
The accelerated growth of the elderly population and the increase in intrafamily violence against this vulnerable group, coupled with the fact that many women are unaware of the laws and protection organs being attacked in silence, encouraged the realization of this work, which aimed to analyze the typicality, characteristics and meanings of the violence against elderly women. The quantitative and qualitative research was carried out in the city of Viçosa/MG, targeting women victims of violence and the following techniques are used: documentary research, semi-structured interview and TALP. The information was collected from the Civil Police, where 17 cases of domestic violence against elderly women were found. In addition, 80 lawsuits filed by women who resorted to protective measures to combat violence were analyzed, four of which were of elderly women. The results showed that domestic violence against women tends to occur in the family environment, demonstrating its asymmetric and conflicting relationships. As for typicality, psychological violence was predominantly, followed by physical violence. Thus, it can be concluded that violence against elderly women is a complex, multifaceted, dynamic and difficult to control phenomenon, which occurs mainly within the family space, causing pain, sadness, anger and humiliation.
\end{abstract}

Keywords: Violence, Old woman, Typicality, Characteristics, Meanings.

\title{
1 INTRODUÇÃO: CONTEXTUALIZAÇÃO DO PROBLEMA E SUA JUSTIFICATIVA
}

O avanço das pesquisas acadêmicas e a crescente divulgação na mídia acerca da Violência Doméstica $^{1}$ levaram a que esse fenômeno social ganhasse reconhecimento e entrasse na agenda das políticas públicas brasileiras há pouco mais de duas décadas.

Uma das formas de expressão da violência doméstica é aquela perpetrada contra as mulheres, vista como o tipo mais generalizado de abuso dos direitos humanos no mundo, e o menos reconhecido. A Assembléia Geral das Nações Unidas, de 1993, definiu oficialmente a violência contra as mulheres, como: Qualquer ato de violência de gênero que resulte ou possa resultar em dano físico, sexual, psicológico ou sofrimento para a mulher, inclusive ameaças de tais atos, coerção ou privação arbitrária da liberdade, quer ocorra em público ou na vida privada” (DAY et al. 2003).

De acordo com os referidos autores, uma em cada três mulheres já foi espancada, coagida ao sexo ou sofreu alguma forma de abuso durante a vida, sendo o agressor, geralmente, um membro de sua própria família, pai, irmão, marido ou companheiro e neto. O fato de um número elevado de vítimas pertencer ao sexo feminino mostra a forte influência da violência de gênero, que ocorre dentro da sociedade em diversos níveis, classes e faixas etárias. Ou seja, na escala social do exercício da dominação-exploração por legitimação do poder ou imposição através da violência, o homem adulto, branco e de classe alta tem predominância sobre as mulheres, crianças, velhos, pobres e negros.

\footnotetext{
${ }^{1}$ Segundo Romeiro (2008), a Violência Doméstica pode ser definida como qualquer tipo de abuso físico, sexual ou emocional praticado não só pelo parceiro íntimo mais também por outros membros, como filhos e netos, contra membros vulneráveis do sistema familiar, como mulheres, crianças e/ou idosos.
} 
Entretanto, como ressalta Motta (2009), a violência contra as mulheres não se restringe à vitimização daquelas em idade jovem, no período reprodutivo, como retrata a grande maioria dos trabalhos. Ao contrário, essa violência continua e assume novas formas velhice adentro, como uma expressão das relações intergeracionais, tanto quanto das relações e desigualdade de gênero, uma vez que é exercida, como vêm demonstrando as pesquisas, principalmente por filhos e netos sobre suas mães e avós, com motivações e manifestações múltiplas, em que as mais comuns são os maus-tratos, a extorsão e apropriação de bens.

Pesquisa realizada por Araújo e Lobo Filho (2009) revelam que no geral, há uma construção psicossocial da violência contra a pessoa idosa, embasada nas suas relações intra-familiares, na qual os agressores são pessoas de confiança, que mantêm uma relação íntima com as vítimas, em sua maioria os filhos.

De acordo com Faleiros (2007), pesquisa realizada em 27 capitais brasileiras sobre a violência contra a pessoa idosa revelou que $12 \%$ dos idosos brasileiros sofrem algum tipo de violência, com manifestações tanto da violência psicológica quanto das violências físicas, financeiras, de abandono e negligência. $\mathrm{O}$ abuso é geralmente praticado por pessoas nas quais os anciãos depositam confiança, como é o caso do próprio filho; sendo a vítima freqüentemente do sexo feminino, com mais de 75 anos, de natureza passiva, complacente, impotente, dependente e vulnerável (PORTELA, et. al., 2012). Outro ponto destacado por Apratto Junior (2010) é que 90\% dos casos de violência contra pessoas acima de 60 anos ocorrem dentro dos lares ou em instituições asilares.

O reconhecimento e o crescimento da consciência social sobre a intensidade do problema da violência contra a mulher fez com que no dia sete de Agosto de 2006, fosse sancionada a Lei 11. 340/06, mais conhecida como Lei Maria da Penha, que tem como objetivo: coibir, prevenir e erradicar a violência doméstica e familiar contra a mulher. O novo texto legal tem como principal mérito reconhecer e definir a violência doméstica em suas distintas manifestações, também prevendo a criação de sistema integrado de proteção e atendimento às vítimas e buscando a aplicação de eficaz sanção penal contra o agressor (BRASIL, 2006).

Desta forma, fica claro o objetivo da lei em defender a mulher contra atos ou omissões que decorram de diferenças discriminatórias ligadas à condição feminina da vítima, abrangendo não só a mulher adulta, mas a mulher-criança, a mulher-adolescente e a mulher-idosa (RODRIGUES, 2009). Enfim, esse aparato social busca desnaturalizar a violência contra a mulher, tornando-a visível e qualificando-a como uma violação dos direitos humanos e como um comportamento criminal. (KNABBEN, 2008). 
Tendo em vista que no Brasil os estudos sobre a Violência Doméstica contra a mulher são compostos basicamente por dados pouco conclusivos, conjugado com o crescimento acelerado do contingente de idosos, fica, então o seguinte questionamento a ser respondido pela pesquisa: Quais são os tipos, características e significados da violência contra a mulher idosa?

Considera-se que a resposta ao referido questionamento possa contribuir para um maior conhecimento acerca do fenômeno da violência contra a mulher idosa, além de subsidiar as políticas, programas e ações de combate à violência contra a mulher.

\section{OBJETIVOS}

O objetivo geral dessa pesquisa consiste em analisar os tipos, características e significados da violência contra a mulher idosa, em face às legislações vigentes de proteção aos direitos do segmento feminino.

\section{REFERENCIAL TEÓRICO}

\subsection{SIGNIFICADOS E TIPOS DE VIOLÊNCIA DOMÉSTICA}

A violência sempre esteve presente na história e não se trata de uma novidade em nossa sociedade. Consiste em um dos graves problemas que atinge a humanidade, estando entre as principais causas de morte de pessoas com idade entre 15 e 44 anos. O uso intencional da força física ou o abuso de poder contra outra pessoa, grupo ou comunidade, traz impactos e consequiências danosas à humanidade.

Como afirmam Silva e Rosseti-Ferreria (2002), vive-se atualmente uma cultura violenta, em um cenário caracterizado pela manutenção do nível de pobreza; desigualdade e concentração de renda; avanço da desestruturação social e degradação da qualidade de vida; além de precariedade no acesso aos direitos básicos (educação, saúde e moradia), que facilita as crises familiares e geram vulnerabilidades, baixa auto-estima, estagnações e invisibilidade social, cujas conseqüências só podem ser de agravamento do quadro da violência.

De acordo com o Relatório Mundial sobre Violência e Saúde, apud Dahlberg e Krug (2007), os tipos de Violência, podem ser: auto-infligida, interpessoal e coletiva (FIG. 1). Esta tipologia fornece uma estrutura útil para a compreensão dos diversos tipos de violência segundo as características daqueles que cometem $\mathrm{o}$ ato violento, considerando a violência na vida cotidiana de indivíduos, famílias e comunidades, na medida em que capta a natureza dos atos violentos, a relevância do cenário, a relação entre agente e vítima e, no caso da violência coletiva, as possíveis motivações para a violência (DAHLBERG; KRUG, 2007). 
A violência auto-infligida é entendida como aquela que compreende o comportamento suicida e agressão auto-infligida; enquanto a violência interpessoal compreende tanto a violência intra-familiar, que ocorre usualmente nos lares, principalmente entre membros da família ou entre parceiros íntimos, quanto à violência na comunidade, entre indivíduos sem relação pessoal, que podem ou não se conhecerem. Por outro lado, a violência coletiva é subdividida em violência social, política e econômica, geralmente cometida por grandes grupos ou países, como por exemplo, crimes de ódio cometidos por grupos organizados, atos terroristas e violência de multidões, guerras e conflitos violentos entre nações e grupos, ataques de grandes grupos motivados pelo lucro econômico.

Dentre todos os tipos de violência existentes a intra-familiar, que envolve principalmente as mulheres, crianças e pessoas idosas, é uma das mais cruéis e perversas, pois, o lar é geralmente identificado como local acolhedor e de conforto, que, no entanto, em casos de violência, passa a ser um ambiente de perigo contínuo que resulta num estado de medo, ansiedade permanente e terríveis humilhações.

Figura 1 - Tipologia da violência

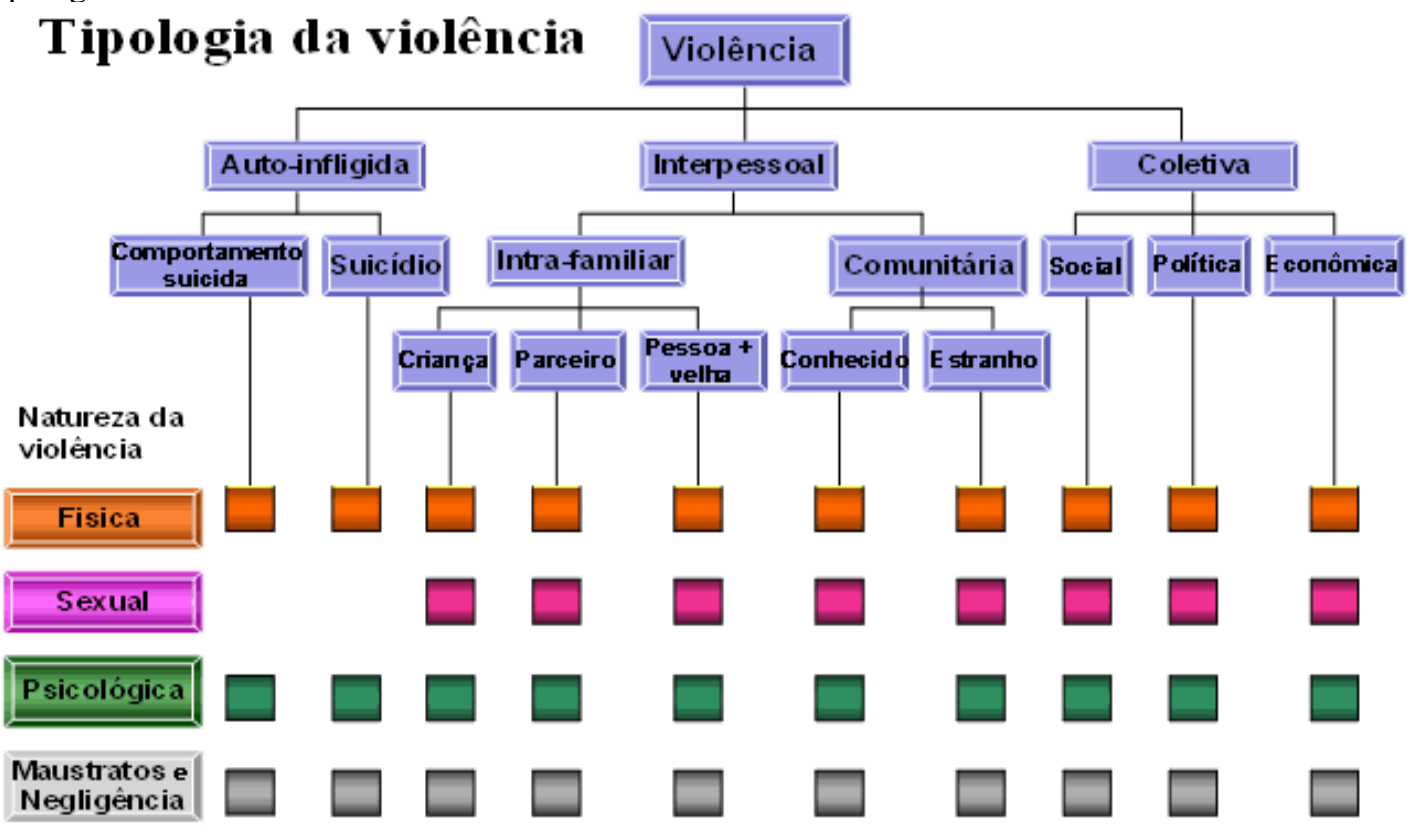

Fonte: World Health Organization. Pre werting Violence: aguide to implementing the recome ndations of rhe Woild Report on Viole nee. 2004.

De acordo com o artigo $7^{\circ}$, da lei 11.340/2006, foram enumeradas as formas de manifestação da violência doméstica e familiar contra a mulher, que de acordo com essa Lei, são elas: violência física, psicológica, sexual, patrimonial, moral.

Por violência física, entende-se que seja qualquer conduta que ofenda a integridade ou a saúde corporal da mulher (DIAS, 2008). Mesmo que a agressão não deixe marcas aparentes, o uso da força 
física que venha a ofender o corpo ou a saúde da mulher irá configurar violência física (Lei 11.340/2006 art. $\left.7^{\circ}, \mathrm{I}\right)$.

Também entendida como violência emocional ou verbal, a violência psicológica se caracteriza por condutas, como: humilhar, ameaçar, discriminar, isolar dos amigos e parentes, controlar e rejeitar (LEI $11.340 / 2006$ art. $7^{\circ}$, II).

O terceiro tipo de manifestação de violência doméstica é a violência sexual, que é entendida como “[...] qualquer conduta que constranja a mulher a presenciar, a manter ou a participar de relação sexual não desejada, mediante intimidação, ameaça, coação ou uso da força;... enfim, que limite ou anule o exercício de seus direitos sexuais e reprodutivos" (LEI 11.340/2006 art. $7^{\circ}$, III).

A violência patrimonial, definida do inciso IV do art. $7^{\circ}$ da Lei 11.340/2006, é vista como: “[...] qualquer ato que implique retenção, subtração, destruição parcial ou total de bens, valores, documentos, direitos e recursos econômicos sobre os quais a vitima possua titularidade". Esse tipo de violência também encontra uma definição no Código Penal entre os delitos considerados contra o patrimônio, tais como furto, dano, apropriação indébita, entre outros. Consiste na recusa do agressor em entregar a vítima seus bens, valores, pertences e documentos, como forma de vingança ou ate como um meio de conseguir obrigá-la a permanecer num relacionamento indesejado.

Por fim, o último tipo de manifestação de violência doméstica, descrita na lei em questão, é violência moral "caracterizada pela desmoralização da mulher, assemelhando-se e entrelaçando-se com a violência psicológica, como dispõe o inciso $\mathrm{V}$ do art. $7^{\circ}$ ". Essa violência ira se configurar sempre que for imputada à mulher conduta que configure calúnia, difamação ou injúria.

Saffioti (1995) ressalta que há uma tendência à rotinização da violência intra-familiar, principalmente contra a mulher, em que a violência física chega a ser duas vezes superior à sofrida por homens. A mesma autora sugere que a violência doméstica, assim como a violência de gênero, ignora os limites entre classe sociais, raça ou etnia. Ressalta que o fato de as classes mais pobres representarem um maior contingente da sociedade faz com que o número de registros apresente mais incidente entre elas, embora possa ocorrer violência em outras classes sociais onde o índice de ocultação parece ser mais elevado, como uma forma de preservar "status". Desta forma, pode-se inferir que os atos de violência são ocultados pela própria família e, por isto, os dados empíricos existentes não colaboram para a compreensão realística desse problema social. 


\section{METODOLOGIA}

\subsection{NATUREZA DO ESTUDO}

Com o intuito de alcançar os objetivos propostos, pretendeu-se neste estudo integrar métodos de pesquisa qualitativa e quantitativa, no intuito de agregar maior rigor metodológico à pesquisa, uma vez que ambas as abordagens se complementam visando uma excelência nos resultados. De acordo com Ponte et. al., (2006), a pesquisa qualitativa se dedica à compreensão dos significados dos eventos, sem a necessidade de apoiar-se em informações estatísticas; já na pesquisa quantitativa o pesquisador não deve envolver-se com o objeto da pesquisa, visando o máximo de objetividade possível no estudo, onde a neutralidade do pesquisador constitui um ponto importante para o estudo. A pesquisa quantitativa procura quantificar os dados, aplicando a análise estatística.

Este estudo caracteriza-se como sendo de natureza exploratório-descritiva, uma vez que busca explorar melhor o tema a ser estudado, buscando proporcionar maior familiaridade com o problema de pesquisa. Como destaca Gil (2005), a pesquisa exploratória tem como objetivo explicar e proporcionar maior entendimento de um determinado problema por ser realizada numa área na qual há pouco conhecimento científico acumulado ou sistematizado. Por outro lado, a pesquisa descritiva se faz presente nesse estudo uma vez que ela destaca-se por expor características de determinada população ou determinado fenômeno.

\subsection{LOCAL DE ESTUDO}

O estudo foi realizado no município de Viçosa/MG, localizado na Zona da Mata do estado de Minas Gerais, a 225 km de Belo Horizonte, capital do estado, com uma área territorial de $299 \mathrm{Km}^{2}$.

A cidade possui uma economia centrada no setor de comércio e serviços, tornando-se assim um pólo comercial e cultural para os municípios de seu entorno. Também possui os melhores meios de comunicação e mercado preferencial, tanto para os produtos e insumos agrícolas quanto de bens manufaturados ou industrializados oriundos de grandes centros urbanos (TIRADENTES, 2005).

Outro aspecto a ser ressaltado é que o desenvolvimento do município é influenciado pela presença da Universidade Federal de Viçosa (UFV) responsável pela pesquisa, ensino e extensão, bem como por outras instituições de ensino superior. O fato do município contar com a presença da UFV, possui uma população flutuante de aproximadamente 12 mil habitantes, somados a uma população estimada de 72.244 habitantes, conforme a contagem populacional feita pelo IBGE (2011), no ano de 2010, sendo que 67.337 pessoas residem no meio urbano e 4.907 no meio rural.

A partir do ano de 2009, o Município de Viçosa/MG passou a contar com a Casa das Mulheres, que visa orientar e dar informações sobre os direitos das mulheres, que sofreram algum tipo de violência. 


\subsection{POPULAÇÃO E AMOSTRA}

A população estudada foi constituída de mulheres, residentes no município de Viçosa/MG, que passaram pelo processo de violência doméstica no ano de 2010, com idade igual ou superior á 60 anos. Para a identificação dessas mulheres foram coletadas informações junto a Policia Civil, onde se constatou 306 casos de ocorrências de violência doméstica contra a mulher no município de Viçosa/MG no ano de 2010. Além disso, para a análise da efetividade dos instrumentos legais de proteção a mulher, foram identificados 80 processos instaurados em 2010, sobre mulheres que recorreram às medidas protetivas de combate à violência.

De acordo com os dados coletados junto à Delegacia e Fórum da Comarca de Viçosa/MG, no ano de 2010 tiveram 17 idosas na delegacia e 4 no Fórum, que deram queixa de violência na policia Militar ou Civil da cidade. Dessa população, foi selecionada uma amostra com o objetivo de examinar as percepções sobre a violência. Esse tipo de amostra, definida por tipicidade, foi composta de mulheres com idade igual ou superior a 60 anos, que de alguma forma acionaram os instrumentos legais de proteção à mulher e ao idoso, como a lei Maria da Penha e o Estatuto do Idoso. Assim, foram entrevistadas cinco mulheres idosas. O tamanho da sub-amostra foi definido em função da possibilidade de contato e consentimento da entrevista.

\subsection{TÉCNICAS DE COLETA DOS DADOS E VARIÁVEIS DE ANÁLISE}

As técnicas de coleta dos dados foram: pesquisa biliográfica e documental, o Teste de Associação Livre de Palavras (TALP) e a entrevista semiestruturada.

Assim, foi feita uma pesquisa bibliográfica sobre a violência conta idosos, bem como uma pesquisa documental sobre a violência doméstica local, em especial contra a mulher. Segundo Oliveira (2007), a pesquisa bibliográfica é uma modalidade de estudo e análise de documentos de domínio científico, tais como livros, periódicos, obras ou documentos que tratem do tema em estudo; enquanto a pesquisa documental caracteriza-se pela busca de informações de interesse em documentos que ainda não receberam tratamento científico (OLIVEIRA, 2007)

O Teste de Associação Livre de Palavras (TALP) é uma técnica bastante difundida no âmbito da Psicologia Social, uma vez que possibilita acesso aos conteúdos periféricos e latentes. Consiste, segundo Nóbrega (2000), em um instrumento que se apoia ao tipo de investigação aberta que permite evidenciar universos semânticos e comuns de palavras face aos diferentes estímulos e sujeitos ou grupos.[...] O estímulo se refere diretamente ao objeto investigado, podendo ser verbal (palavra, expressão, idéia, frase, provérbio) [...]. Assim foi utilizada para identificar os significados da violência, sendo perguntado às 
idosas: "o que lhe vem à sua mente (cabeça) quando digo a palavra violência?" fale as primeiras palavras que para a sra significa violência. "Para sra o que é a violência contra pessoas idosas?".

A entrevista semiestruturada realizada junto às mulheres idosas serviu de guia para trazer uma série de questões específicas sobre as características da violência, com partes mais estruturadas, permitindo obter detalhes, além de questões menos estruturadas, abertas, onde o entrevistador pode acrescentar perguntas de esclarecimento, como destacam Laville e Dionne (2008).

Em termos das fases da pesquisa, primeiramente foi realizada uma consulta nos registro de eventos de defesa social (REDS), antigo boletim de ocorrência da Delegacia de Policia Civil de Viçosa/MG, do ano de 2010, para verificar a tipicidade e características da violência. Após o levantamento das informações vinculadas aos processos na Vara Criminal do Fórum da Comarca de Viçosa/MG e na Delegacia de Policia Civil da cidade de Viçosa/MG foram feitos contatos com as possíveis pesquisadas (idosas), verificando-se a possibilidade de conceder informações para a pesquisa.

Em seguida, as informações foram complementadas com entrevistas semiestruturadas que possuíam questões abertas e fechadas. As mulheres idosas entrevistadas assinaram o termo de consentimento livre e esclarecido, após receberem os esclarecimentos acerca dos objetivos e aspectos éticos da pesquisa, garantindo-lhes o sigilo.

As entrevistas foram aplicadas na casa da entrevistada e duraram em média, uma hora, sendo gravadas, quando consentidas pelo sujeito da pesquisa, ou escritas no momento da entrevista. Posteriormente, as entrevistas foram transcritas e ou reescritas para que não fosse perdida nenhuma informação.

\subsection{PROCEDIMENTOS DE ANÁLISE DOS DADOS}

Para análise dos dados quantitativos, referente ao perfil das entrevistadas e tipos de violência, cada variável foi estudada isoladamente, usando métodos estatísticos descritivos, em termos de média e freqüência.

As questões subjetivas, após terem sido transcritas, foram analisadas categoricamente, por meio do tratamento qualitativo dos dados, fazendo-se uso da análise de conteúdo (BARDIN, 2011). Desse modo, após sucessivas leituras das entrevistas transcritas, foram elaboradas categorias analíticas para o estudo, com base nos objetivos propostos e no referencial teórico apresentado. 


\section{RESULTADOS E DISCUSSÃO}

\subsection{TIPICIDADE E CARACTERÍSTICAS DA VIOLÊNCIA CONTRA AS MULHERES IDOSAS}

Com a finalidade de demonstrar os tipos de violência que as mulheres idosas sofreram no ano de 2010, no município de Viçosa/MG, o Quadro 1, mostra dados tanto da Delegacia de Policia Civil quanto da Vara Criminal da Comarca do Fórum.

Quadro 1: Tipos de Violência Doméstica Contra a Mulher no Município de Viçosa/MG

\begin{tabular}{|c|c|c|c|}
\hline \multicolumn{4}{|c|}{ TIPOS DE VIOLÊNCIA } \\
\hline \multicolumn{2}{|c|}{ TIPOS DE VIOLÊNCIA } & $\begin{array}{c}\text { Delegacia de Policia } \\
\text { Civil }(\%)\end{array}$ & $\begin{array}{l}\text { Vara Criminal do Fórum } \\
\qquad(\%)\end{array}$ \\
\hline 1. & PSICOLÓGICA & 53,0 & 75,0 \\
\hline 2. & FÍSICA & 17,6 & - \\
\hline 3. & FÍSICA/PSICOLOGICA & 17,6 & - \\
\hline 4. & PATRIMONIAL & 5,9 & - \\
\hline 5. & PATRIMONIAL/PSICOLOGICA & 5,9 & - \\
\hline 6. & FISICA/PATRIMONIAL & - & 25,0 \\
\hline & TOTAL & 100,0 & 100,0 \\
\hline
\end{tabular}

Fonte: Dados da Pesquisa na Delegacia de Policia Civil de Viçosa/MG e da Vara Criminal da Comarca do Fórum de Viçosa/MG, no ano de 2010.

Como foi possível observar no Quadro 1, nem sempre a mulher idosa vítima de violência doméstica sofre apenas um tipo de violência, podendo muitas vezes sofrer dois tipos. Entretanto, a violência psicológica foi o tipo que mais atingiu as mulheres idosas que notificaram a ocorrência na Delegacia de Policia Civil, bem como aquelas que decidiram representar contra o agressor e tiveram o processo encaminhado para a Vara Criminal da Comarca do Fórum de Viçosa, no ano de 2010. Além da violência psicológica aparecer sozinha na maior parte dos casos, ela também é conjugada a outros tipos de violência, como é o caso da patrimonial e física.

Esses dados confirmam o mapa da violência doméstica contra as mulheres viçosenses, elaborado pelos projetos "Casa das Mulheres" e "Educação para o Trabalho da Vigilância em Saúde da UFV", no período de maio de 2009 a junho de 2010, que relatam que a violência psicológica foi o tipo de violência mais citado (34\%), seguido da violência física (32\%) e a ocorrência dos dois tipos física e psicológica $(14 \%)$.

Entre os tipos de violências notificadas pelas mulheres idosas no município de viçosa, foi possível observar à ocorrência da violência patrimonial, que, além de aparecer nas denúncias isoladas, também 
esteve presente conjugada a violência física e a psicológica. Contudo, fica claro, a partir dos dados, que a violência, seja qual for a sua forma, aparece tanto sozinha quanto conjugada a outros tipos de violência, demonstrando assim sua natureza complexa e multifacetada.

\subsection{PERCEPÇÃO DAS VITIMAS QUANTO ÀS CARACTERÍSTICAS E SIGNIFICADOS DA VIOLÊNCIA}

Para análise da percepção da vítima sobre o fenômeno da violência doméstica foram selecionadas cinco mulheres idosas, conforme o perfil apresentado no Quadro 2.

Quadro2: Perfil Socioeconômico das Mulheres Idosas Entrevistadas, Viçosa/MG, 2012.

\begin{tabular}{|c|c|c|c|c|c|c|c|c|}
\hline $\begin{array}{c}\mathrm{N}^{\circ} \\
\text { Entrev. }\end{array}$ & Idade & $\begin{array}{c}\text { Estado } \\
\text { Civil }\end{array}$ & $\begin{array}{c}\text { Relação com o } \\
\text { Agressor }\end{array}$ & Escolarid. & Ocupação & $\begin{array}{c}\text { Renda } \\
\text { Mensal }\end{array}$ & Religião & Raça \\
\hline 1 & 61 & Solteira & Irmão & $\begin{array}{c}\text { Ens. } \\
\text { Médio } \\
\text { completo }\end{array}$ & Faxineira & 1 S/M & Católica & Parda \\
\hline 2 & 69 & Casada & Marido & $\begin{array}{c}\text { Até a 5 } \\
\text { serie }\end{array}$ & Aposentada & 1 S/M & Católica & Negra \\
\hline 3 & 75 & Viúva & Neta & $\begin{array}{c}\text { Até a 5 } \\
\text { serie }\end{array}$ & Do lar & 70,00 & Católica & Branca \\
\hline 4 & 61 & Casada & Irmão & $\begin{array}{c}\text { Até a } 6^{\circ} \\
\text { serie }\end{array}$ & Domestica & 1 S/M & Católica & Branca \\
\hline 5 & 64 & Casada & Marido & $\begin{array}{c}\text { Até a } 4^{\circ} \\
\text { serie }\end{array}$ & Do lar & 1 S/M & Católica & Branca \\
\hline
\end{tabular}

Fonte: Dados da pesquisa (2012).

O perfil sócio econômico das mulheres idosas entrevistadas revelou que três delas eram casadas, uma era solteira e uma era viúva. A maior parte das mulheres idosas entrevistadas era de cor branca. E, quanto à religião, responderam serem todas católicas. Com respeito à escolaridade, uma delas tinha o ensino médio completo e o restante possuía ensino fundamental incompleto. Constatou-se, também, que todas as mulheres idosas possuíam renda mensal baixa, variando de setenta reais a um salário mínimo.

No que tange a ocupação, notou-se que todas as mulheres idosas entrevistadas estão envolvidas com afazeres domésticos, sendo que duas dessas mulheres recebiam remuneração por esses serviços, trabalhando fora de casa e o restante trabalhavam em suas próprias casas; aumentando-se, assim, a dependência financeira para com outras pessoas, sejam elas marido ou outros parentes.

Em se tratando da relação vítima/agressor todas as mulheres da amostra pesquisada possuíam relação intima com o agressor, sendo o marido e o irmão os que mais apareceram como agressores da amostra em estudo, embora a neta tenha aparecido em um caso. Isso comprova a pesquisa realizada por Minayo (2003) que demonstrou que 90\% dos atos de violência acontecem nos lares dos idosos e que 2/3 
são praticados por seus filhos, netos, genros e cônjuges, ou ate por outros parentes, como é o caso do irmão, observado na pesquisa em questão.

No que tange ao tipo de violência sofrida pelas mulheres idosas entrevistadas, três delas disseram ter sofrido mais de um tipo de violência, ou seja, a violência caracterizava-se como sendo multifacetada. Elas responderam ter sofrido violência física, psicológica, moral/verbal e patrimonial. Já as outras duas, responderam ter sofrido somente a violência física.

Neste estudo foi possível observar que todas as mulheres idosas foram vítimas da violência física, que é caracterizada pela violação da integridade corporal, podendo se manifestar através de agressões físicas, com uso ou não de objetos: tapas, murros, chutes, facada e tiro. $\mathrm{Na}$ fala abaixo, é possível verificar o relato da vitima sobre esse tipo de violência:

[...] me agrediu sem motivos, pois não fiz nada contra ele, ele bebe muito e também era muito mulherengo, depois que começou a beber ele passou a me agredir. (Entrevistada 2).

A violência patrimonial, também pelas mulheres idosas, pode ser materializada nos casos de retenção, subtração, destruição parcial ou total de objetos, documentos pessoais, bens, valores ou recursos econômicos. O depoimento abaixo mostra como esse tipo de violência foi vivenciado pela entrevistada:

[...] ele quis que eu saísse da minha casa pra colocar a "outra" pra morar na minha casa. Eu não aceite ai deu confusão ele me tirou a força da minha casa que eu ajudei a construir. (Entrevistada $5)$.

A fala acima retrata a violência patrimonial que a mulher idosa entrevistada sofreu, pois, mesmo sem saber que se tratava de um tipo de violência, ela relatou tais fatos, enquanto falava sobre os tipos de violência que havia sofrido.

No que se refere à violência moral/verbal, que se trata de qualquer conduta que se configure em difamação, calúnia ou injúria, também pode ser observada na fala da mulher entrevistada como mostrado abaixo:

[...] ele me "xingava" muito de todos os nomes e no meio da rua, todos os vizinhos escutaram. (Entrevistada 5).

As falas foram usadas para facilitar a identificação do fenômeno da violência, uma vez que foi possível observar que o cotidiano das mulheres idosas vitima de violência era marcado por mais de um tipo de violência.

$\mathrm{Na}$ análise sobre o Significado da Violência foi aplicado o Teste da Associação Livre das Palavras perguntando-se às mulheres idosas quais eram as primeiras palavras que lhes vinham na cabeça, quando 
ouviam a palavra violência, sendo que as palavras ditas com maior frequiência por elas foram: agressão, dor, tristeza, raiva e humilhação. Alguns elementos foram agrupados às palavras citadas acima como: agressão (bater, murro, soco, tapa, violência física, briga e confusão); tristeza (angústia, preocupação e muita tristeza); dor; raiva (ódio, rancor e revolta) e humilhação, a fim de facilitar o entendimento.

A palavra agressão foi citada por todas as mulheres idosas, e isso se deve ao fato de que a violência para elas vai muito além da violência física, pois ela traz o sentimento de dor, que é uma dor psicológica que vai ficar marcada para sempre na vida delas. Portanto, a dor e a tristeza mencionadas pelas vítimas estão relacionadas às consequências da vivência de violência, que comprometem e interferem no desenvolvimento físico e psicológico. O sentimento de raiva esta ligado à revolta que elas têm por terem sofrido a violência por agressores em que elas depositavam confiança. Já a dor e a tristeza que elas mencionaram estão associadas às conseqüências que a violência acarretou na vida delas. A raiva, contudo, é um sentimento de revolta que a mulher idosa carrega consigo, enquanto o sentimento de humilhação aparece pela impotência frente à violência sofrida.

\section{CONCLUSÃO}

A violência doméstica contra a mulher idosa é um fato real na sociedade brasileira, e a tolerância a esse tipo de violência pode ser vista como uma ofensa aos seus direitos, de liberdade, saúde, segurança e proteção. Frente a esse contexto, surge a Lei Maria da Penha e o Estatuto do Idoso a fim de diminuir a violência contra a mulher e o idoso, buscando conscientizar ao agressor de que ele deve ser punido, uma vez que seus atos não são considerados normais.

A violência doméstica contra a mulher idosa em Viçosa/MG ocorreu principalmente no ambiente familiar, sugerindo que o lar não é mais um lugar de tranqüilidade e segurança, mas sim um local onde se destacam relações assimétricas e de poder. Houve uma grande ocorrência dos filhos como agressores, o que aumenta a passividade da vítima, uma vez, que ela teme a perda dos laços afetivos com a família.

No que diz respeito à tipicidade da violência, nem sempre a mulher idosa sofre apenas uma forma de violência. Embora, haja o domínio da violência psicológica, seguida da violência física, além da violência patrimonial e da moral/verbal, que estão associadas a desentendimentos decorrentes de perdas materiais ou simbólicas de bens ou objetos e também ao uso de entorpecentes por parte dos agressores.

As implicações da violência na vida da mulher idosa são múltiplas, o que as leva a um sentimento de tristeza, dor, raiva e humilhação, por ter os direitos privados, sofrer perdas financeiras e principalmente afetivas. 


\section{REFERÊNCIAS}

APRATTO JUNIOR, Paulo Cavalcante. A violência doméstica contra idosos nas áreas de abrangência do Programa Saúde da Família de Niterói (RJ, Brasil).Ciênc. saúde coletiva.vol.15, n.6, p. 2983-2995, 2010.

ARAÚJO, L. F.; LOBO FILHO, J. G. Análise Psicossocial da Violência contra Idosos. Psicologia: Reflexão e Crítica, v. 22, n. 1, p.153-160, 2009.

BARDIN, L. Análise de conteúdo. Lisboa: Edições 70, 2011

BRASIL. Lei n. 11.340, de 7 de agosto de 2006.Dispõe sobre a criação de juizados de violência doméstica e familiar contra a mulher e dá outras providências. In:Diário Oficial da União. Seção 1:1. Brasília (DF), 2006.

CASA DAS MULHERES. Pacto Municipal de Enfrentamento da Violência contra a Mulher em Viçosa. Disponível: < http://projetocasadasmulheres.blogspot.com>. Acesso: 07/06/2013.

DAHLBERG, Linda L.; KRUG, Etienne G. Violência: Um problema global de saúde pública. Ciência \& Saúde Coletiva, 11(Sup), p.1163-1178, 2007.

DAY, V. P.; TElleS, L. E. B.; ZORATTO, P. H. et al. Violência doméstica e suas diferentes manifestações. Revista de Psiquiatria, v. 25, supl. 1, p. 9-21, 2003.

DIAS, M. B.. A lei Maria da Penha na justiça: a efetividade da Lei 11.340/2006 de combate à violência doméstica e familiar contra a mulher. São Paulo: Editora Revista dos Tribunais, 2008.

FALEIROS, V. P. Violência contra a pessoa idosa ocorrências, vítimas e agressores. Brasília, DF: Universa. 2007.

GIL, Antonio Carlos. Como elaborar projetos de pesquisa. 4. ed. São Paulo: Atlas, 2005.

INSTITUTO BRASILEIRO DE GEOGRAFIA E ESTATÍSTICA - IBGE. Cidades@ - Disponível em: <http://www.ibge.gov.br/home/>. Acesso em: 15/06/2013.

KNABBEN, D. Prevalência e perfil do trauma físico em mulheres agredidas submetidas ao exame de corpo de delito no Instituto Médico Legal (IML) de Criciúma. Monografia de Conclusão do Curso de Medicina da UNESC, Criciúma, 2008.

LAVILLE, C.; DIONNE, J. A construção do saber: manual de metodologia da pesquisa em ciências humanas. n Porto Alegre: Editora Artes Médicas Sul Ltda; Belo Horizonte: Editora UFMG, 2008.

MINAYO, M. C. S. Violência contra idosos: Relevância para um velho problema. Cadernos de Saúde Pública, v.11, n.3, p. 783-791, 2003.

MOTTA, Alda Brito da. Violência contra as mulheres idosas- Questão feminista ou questão de gênero? In: Congresso da LASA (Associação de Estudos Latino-Americanos), Rio de Janeiro, Brasil, de 11 a 14 de junho de 2009.

NÓBREGA, S. M. O teste de associação livre de palavras. Maiorias e minorias do conformismo à inovação. In: Moreira, A.S.P.; Oliveira, D.C., org. Estudos Interdisciplinares de Representação Social. Goiânia: Ed. A-B, 2000. 
OLIVEIRA, M. M. Como fazer pesquisa qualitativa. Petrópolis, Vozes, 2007.

PONTE, V. M. R. Análise das Metodologias e Técnicas de Pesquisas Adotadas nos Estudos Brasileiros sobre Balanced Scorecard: Um Estudo dos Artigos Publicados no Período de 1999 a 2006. Disponível em: <http://www.furb.br/congressocont/_files/EPC\%20079.pdf>. Acessado em: 15/06/2013.

PORTELA, Katrinna M.P; BARRETO, Luciana S.; TORRES, Maria M. S. M. Violência contra o idoso: Um mal que cresce a cada dia na sociedade. Disponível em <http://www.webartigos.com>. Acesso 07/06/2013.

RODRIGUES, L. L.; COELHO, R. P.; LIMA R. R.. A Contribuição da lei 11.340/06 (lei Maria da Penha) para o combate da Violência Doméstica e Familiar contra a Mulher. Fortaleza: Universidade de Fortaleza, 2009. Disponível em: <http://www.conpedi.org.br>Acesso: 07/06/2013.

ROMEIRO, J. A Lei Maria da Penha e os desafios da institucionalização da "violência conjugal" no Brasil.Seminário Internacional Fazendo Gênero: "Construindo novas relações de gênero: a presença feminina nos territórios do saber”. Florianópolis: (Editora), 2008.

SAFFIOTI, H. I. B. Já se mete a colher em briga de marido e mulher. São Paulo em Perspectiva. v.13, n. 4, p. 82-91, 1999.

SILVA, A. P. S.; ROSSETI-FERREIRA, M. C. Continuidade/Descontinuidade no envolvimento com o crime: Uma discussão crítica da literatura na psicologia do desenvolvimento. Psicologia: Reflexão $e$ Crítica. Porto Alegre, v.15, n. 3, 2002.

TIRADENTES, L. Lugar, paisagem e turismo na Microrregião de Viçosa. In: Simpósio Nacional Sobre Geografia, Percepção e Cognição do Meio Ambiente - SINPEC. Anais... Londrina, PR, v. 1, p. 01-16, 2005. 